03

\title{
Взаимодействие газовых струй со сверхзвуковым поперечным потоком в канале
}

\author{
(c) М.П. Голубев, М.А. Гольдфельд ॠ \\ Институт теоретической и прикладной механики им. С.А. Христиановича СО РАН, Новосибирск, Россия \\ ฯ E-mail: gold@itam.nsc.ru
}

Поступило в Редакцию 5 сентября 2018 г.

Представлены результаты исследования проникновения звуковых струй водорода в поперечный поток с числом Маха 4 и их влияния на структуру течения в канале с обратным уступом. Показано, что проникновение струи в канале отличается от проникновения в свободном потоке и не может быть предсказано на основе использования известных эмпирических соотношений. Увеличение коэффициента динамического напора струи водорода приводит к изменению структуры течения и распределения давления в области инжекции струи и вниз по потоку за уступом вследствие влияния отраженной ударной волны и ее взаимодействия с пограничным слоем на стеке.

DOI: 10.21883/PJTF.2019.01.47158.17517

Струя в поперечном потоке является одним из канонических потоков для изучения турбулентных течений как на фундаментальном, так и на прикладном уровне. Несмотря на относительную простоту, это течение позволяет исследовать трехмерность течения и отрыва потока, пристенные эффекты и вихревые структуры [1]. Струя в поперечном потоке применяется во многих технологических процессах: от промышленных горелок или двигателей внутреннего сгорания до систем подачи топлива и процесса управления вектором тяги в гиперзвуковых силовых установках. Проведенный большой объем исследований позволил получить подробные данные для таких течений на плоской пластине как при дозвуковых, так и при сверхзвуковых скоростях потока [2]. Поперечные струи в потоке используются в качестве простых конфигураций для подачи топлива в гиперзвуковых воздушно-реактивных двигателях. Известно, что поперечная струя представляет собой более эффективное средство смешения, чем свободная струя [3]. Хотя изучению взаимодействия струй с поперечным потоком уделяется большое внимание, в основном исследования были сосредоточены на одиночном инжекторе с различными формами звукового сопла и подаче при различных углах и режимах течения [4]. В последнее время все больше внимания уделяется изучению взаимодействия парных и многоструйных конфигураций $[5,6]$.

Со времени первых обобщений известных экспериментальных данных [7] были получены важные и разнообразные сведения о характеристиках и структуре потока, включая трехмерные особенности таких течений. Обзор этих исследований можно найти, например, в [8]. Вместе с этим анализ известных экспериментальных и расчетных данных показывает, что изучение взаимодействия струй с поперечным сверхзвуковым потоком проводилось главным образом на плоской пластине, что не характерно для течений в каналах. Кроме того, в литературных источниках нет информации об особенностях взаимодействия струй при встречной инжекции струй с противоположных стенок. В этом случае возникают дополнительные волновые структуры, которые влияют на глубину проникновения струи и характеристики потока в канале.

Цель настоящей работы состоит в изучении взаимодействия встречных струй водорода с поперечным высокоэнтальпийным потоком при числе Маха 4, структуры течения в канале с внезапным расширением в зависимости от давления подачи газа, а также в определении характеристик потока в условиях, близких к условиям реального полета.

Экспериментальная установка была выполнена в виде прямоугольного канала, состоящего из сверхзвукового сопла, изолятора и инжекторной секции с поперечным размером $100 \times 100 \mathrm{~mm}$ (рис. 1). Форкамера аэродинамической трубы IT-302М использовалась в качестве источника высокоэнтальпийного газа [9]. Эксперименты проводились в режиме присоединительного трубопровода. Особенность этой установки состоит в том, что она позволяет получить параметры потока с высокой энтальпией в широком диапазоне условий испытаний благодаря промежуточному дросселированию. В качестве основного газа использовался азот, чтобы исключить воспламенение водорода при температурах основного потока выше температуры воспламенения. На входе в канал устанавливался уступ высотой $25 \mathrm{~mm}$. Модель была оснащена оптическими стеклами для визуализации потока. Подача водорода осуществлялась на верхней и нижней стенках через круглые отверстия диаметром $2.8 \mathrm{~mm}$ под углом $45^{\circ}$ или 90․ Испытания проводились при следующих условиях на входе в канал: число Маха 4, полная температура 1400-1900 K, статическое давление $0.08-0.12 \mathrm{MPa}$. Во время испытания расход азота изменялся от 2 до $9.5 \mathrm{~kg} / \mathrm{s}$, расход водорода — от 0.048 до $0.27 \mathrm{~kg} / \mathrm{s}$.

В ходе испытаний измерялись полное давление и температура газа в первой и второй форкамерах установки, расход основного и вторичного газа, распределение 

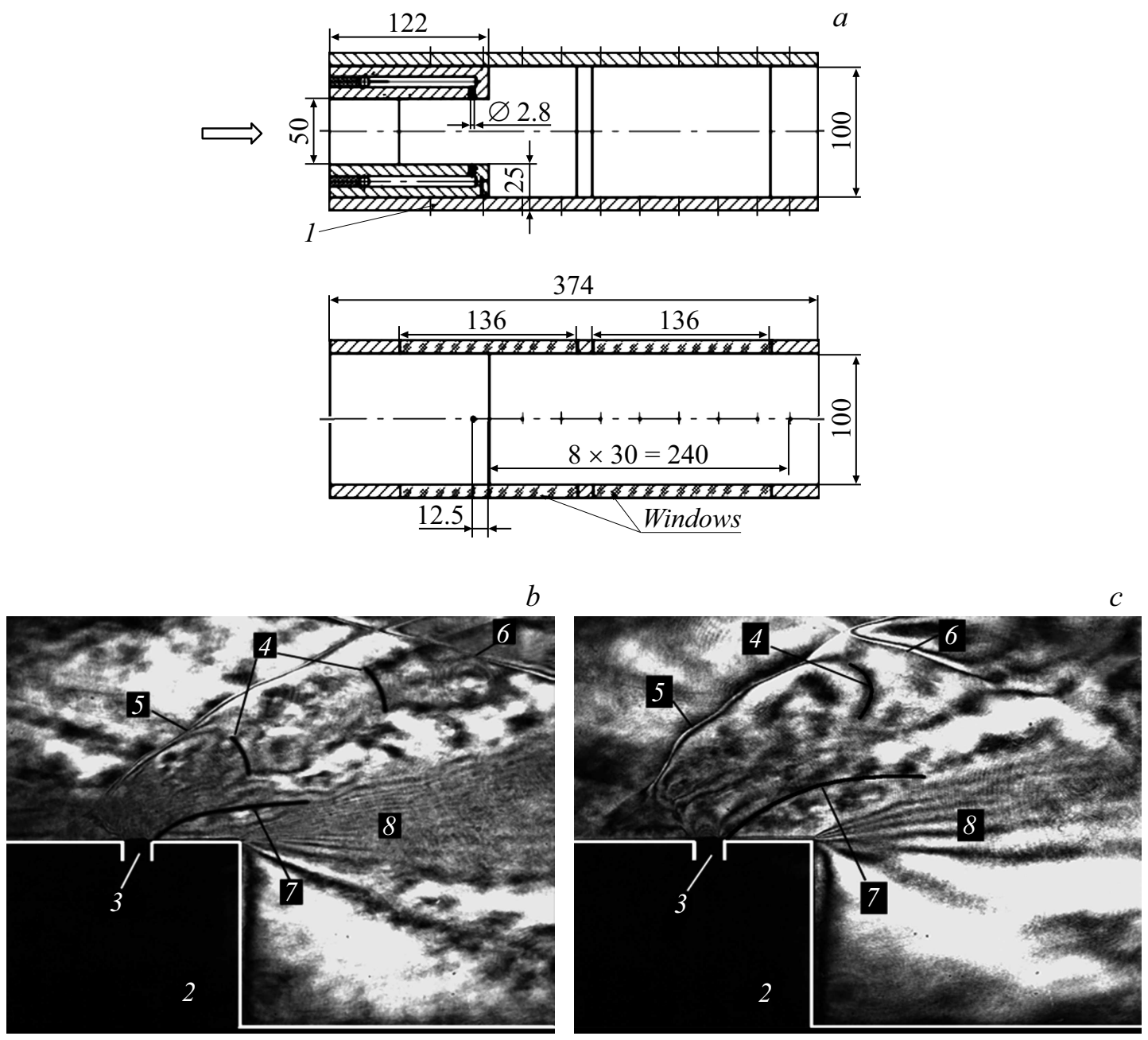

Рис. 1. Схема модели $(a)$ и структура течения в канале при значениях параметра $J=2.1(b)$ и $8.2(c)$. Все размеры приведены в mm. 1 - канал подачи газа, 2 - уступ, 3 - инжектор, 4 - диск Маха, 5 - головной скачок, 6 - отраженный скачок, 7 вихрь за струей, $8-$ веер волн разрежения.

статического давления на стенках канала и донное давление. Большое чтсло измерительных точек (более 60) позволило получить подробные распределения статического давления, включая донное давление. Визуализация потока осуществлялась с помощью адаптивных визуализирующих транспарантов, работающих на основе эффекта насыщения поглощения (SA-AVT). Этот метод является развитием методики Теплера с использованием лазерного излучения и самоиндуцирующихся фильтров типа Цернике [10].

Понимание структуры потока в этих условиях важно, поскольку помогает определить траекторию струи, ее проникновение и влияние на эффективность смешения топливовоздушной смеси. В работах $[3,7]$ показано, что коэффициент динамического напора струи $J$ является наиболее важным параметром для определения проникновения струи в поперечный поток. Он рассчитывается по формуле $J=\left(\rho V^{2}\right)_{j} /\left(\rho V^{2}\right)_{c f}$, где $\rho$ и $V$ - плотность и скорость, нижние индексы $j$ и $c f$ относятся к струе и поперечному потоку, соответственно. Влияние этого параметра является определяющим не только для характеристик струи, но и для всей структуры потока в канале.

На картинах визуализации инжекции струи водорода можно видеть головную ударную волну перед струей, бочкообразный скачок и диск Маха (рис. 1,b). Следует отметить, что на форму струи влияют отраженная ударная волна 6 и веер волн разрежения на кромке уступа 8. На головной ударной волне имеются изломы, которые отчетливо видны на изображениях визуализации течения. Эти перегибы непосредственно связаны с турбулентными вихрями в инжектируемой струе. Их интенсивность усиливается при увеличении давления подачи водорода, что следует из сравнения изображений на рис. $1, b$ и $c$. При низких значениях параметра $J=2-3$ ударная волна перед струей остается практически прямолинейной.

По результатам обработки изображений визуализации течения была получена зависимость угла наклона ударной волны от параметра $J$ (рис. 2,a). Этот угол 
относится к начальной части струи, но без учета отрыва пограничного слоя на стенке перед струей. Сравнение углов наклона ударной волны с данными для струи на плоской пластине в свободном потоке при тех же условиях [11] показывает, что эти данные различаются слабо. Следует отметить, что эти результаты нужно интерпретировать осторожно, поскольку они не дают полной информации о трехмерной структуре ударных волн и других трехмерных свойствах потока. В двумерном потоке рост угла наклонной ударной волны непосредственно означал бы увеличение общих потерь давления в зависимости от наклона ударной волны. Из-за трехмерных эффектов общее увеличение потерь давления может уменьшаться при увеличении коэффициента динамического напора струи $J$.

Результаты определения положения первого диска Маха в водородной струе $h / d(d-$ выходной диаметр сопла), полученные по изображениям, в зависимости от параметра $J$ представлены на рис. 2, $b$. Эти данные показывают, что изменение траектории центра диска Маха в наших экспериментах при увеличении параметра $J$ отличается от соответствующего изменения траектории на пластине в свободном потоке. Глубина проникновения в поперечном направлении намного меньше, чем на плоской пластине. В продольном направлении диск Маха примерно сохраняет свое положение или даже может смещаться вверх по потоку при $J>9$. Причина такого изменения траектории струи заключается в том,
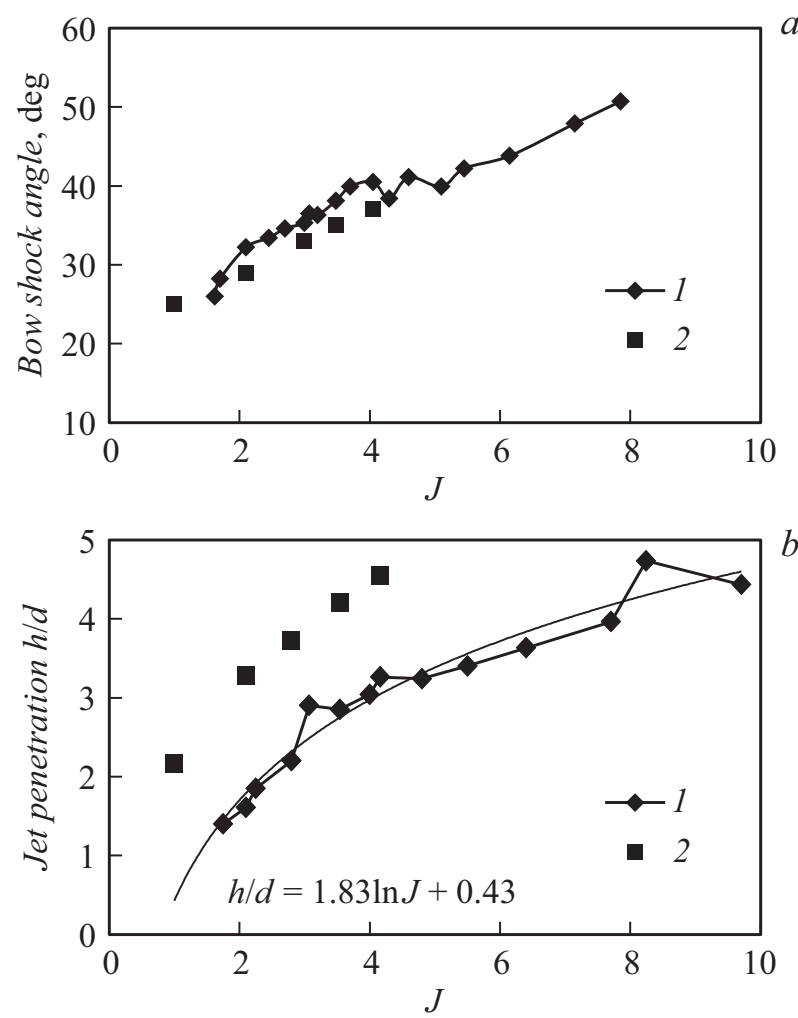

Рис. 2. Угол наклона головного скачка перед струей $(a)$ и положение диска Маха $(b) .1$ - данные настоящей работы, 2 - данные $[11] ; h / d$ - аппроксимирующая зависимость.

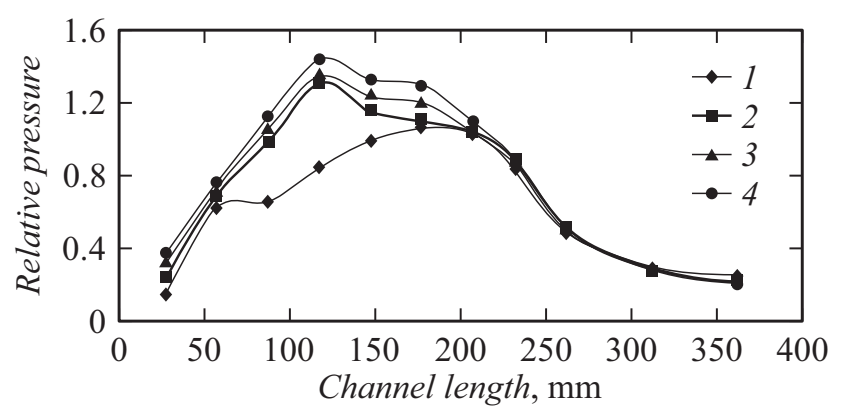

Рис. 3. Влияние коэффициента динамического напора струи на распределение давления по длине канала при значениях параметра $J=0(1), 3.9(2), 6.4(3), 8.8$ (4).

что по мере увеличения коэффициента динамического напора струи область между головной и отраженной ударной волной сужается, что приводит к росту противодавления, которое создает условия, препятствующие смещению диска Маха вниз по потоку.

Анализ структуры течения по картинам визуализации для диапазона значений параметра $J$ от 1.67 до 9.8 показал, что увеличение параметра $J$ приводит не только к изменению формы и траектории водородной струи, но и к изменению характеристик потока в зоне рециркуляции за уступом и вниз по потоку за ней. Именно в этой области происходит взаимодействие отраженной ударной волны с пограничным слоем на стенке и его отрыв. Было установлено, что при увеличении коэффициента динамического напора струи ширина веера волн разрежения уменьшается, что видно из сравнения данных рис. $1, b$ и $c$. При максимальных значениях $J>9.2$ веер волн разрежения полностью исчезает, что подтверждено проведенной визуализацией течения. Одновременно происходит слияние зоны отрыва пограничного слоя и области рециркуляции за уступом. По существу, образуется общая область отрыва, включающая зону рециркуляции за уступом и зону отрыва пограничного слоя, вызванную отраженной ударной волной. В результате значительного увеличения этой области отраженная ударная волна не достигает стенки, а ее длина значительно уменьшается при $J>9.4$.

Изменение структуры потока за уступом приводит к увеличению донного давления. Результаты измерения давления показали, что относительное давление увеличивается более чем в 2 раза на расстоянии $x=30 \mathrm{~mm}$ от уступа (рис. 3) при двукратном увеличении параметра $J$. Поперечная водородная струя влияет не только на давление в донной области, но и на распределение давления вниз по потоку на большом расстоянии от уступа. Измерение распределения давления по длине канала вниз по потоку за уступом показывает, что увеличение коэффициента динамического напора струи сопровождается ростом давления на начальном участке канала при $x<220 \mathrm{~mm}$, как следует из данных рис. 3. Можно видеть, что максимальное увеличение относительного давления достигается на длине примерно $100 \mathrm{~mm}$ от 
уступа и достигает 70\%. Одновременно увеличивается размер области течения, в которой это давление возрастает. Такой эффект обусловлен увеличением интенсивности головной и отраженной ударных волн при росте параметра $J$ и увеличением размера и формы вихревой области 7 непосредственно за струей на уступе (рис. 1,c). Физически пик этой области повышенного давления соответствует отрыву пограничного слоя при воздействии отраженной ударной волны.

Таким образом, проведенные исследования позволяют сделать следующие выводы.

1. Глубина проникновения струи в исследуемом течении значительно меньше, чем в свободном потоке без встречной инжекции.

2. Увеличение коэффициента динамического напора струи сопровождается увеличением зоны отрыва за уступом и значительным ростом давления в донной области.

3. Получена эмпирическая зависимость для определения положения диска Маха в канале при встречной инжекции газа. Показано, что в этих условиях глубина проникновения может уменьшаться примерно в 1.6 раза.

Работа выполнена при фининсовой поддержке РФФИ, грант № 17-08-01158

\section{Список литературы}

[1] Mahesh K. // Annul. Rev. Fluid Mech. 2013. V. 45. P. 379-407.

[2] Karagozian A.R. // Prog. Energy Combust. Sci. 2010. V. 36. P. 531-553.

[3] Rana Z., Thornber B., Drikakis D. // Phys. Fluids. 2011. V. 23. N 046103. P. 1-20.

[4] Viti V., Neel R., Schetz J.A. // Phys. Fluids. 2009. V. 21. N 04101. P. 1-16.

[5] Pudsey A.S., Wheatley V., Boyce R.R. // J. Propulsion Power. 2015. V. 31. P. $144-155$.

[6] Landsberg $W$., Wheatley $V$., Veeraragavant A. // AIAA Journal. 2016. V. 54. P. 3692-3700.

[7] Billig F.S., Orth R.C., Lasky M. // AIAA Journal. 1971. V. 9. P. $1048-1058$.

[8] Huang W. // Aerospace Sci. Technol. 2016. V. 50. P. 183-195.

[9] Maslov A.A., Shumsky V.V., Yaroslavtsev M.I. // Thermophys. Aeromech. 2013. V. 20. P. 535-546.

[10] Pavlov Al.A., Golubev M.P., Kosinov A.D., Pavlov A.A. // AIP Conf. Proc. 2017. V. 1893. N 1. P. 030068

[11] Jacobsen L.S., Schetz J.A., Ng W.F. // J. Propulsion Power. 2000. V. 16. P. $216-226$. 